\title{
A Descriptive Study of Chlorhexidine as a Disinfectant in Cleft Palate Surgery
}

\author{
Gieljam Johannes Roode, BChD, MSc(Odont-Oral Surg); and \\ Kurt-Wilhelm Bütow, MChD(in MFOSurg), Dr Med Dent, DSc(Odont)
}

\begin{abstract}
Objectives: Chlorhexidine is seen as the golden standard of disinfectants. It is widely used to clean surgical sites; however, many studies indicate resistance of pathogens to chlorhexidine. One study indicated that pathogenic microorganisms were isolated from the soft palate cleft region in $57 \%$ of patients with facial clefts. The objectives of our study were to determine (I) if chlorhexidine application is effective in removing pathogens from the surgical site in these patients, and (2) if any pathogens are isolated, determine if they are resistant to other antimicrobials.
\end{abstract}

Design: A descriptive observational study.

Settings: A private practice that specializes in facial cleft surgery, with a country-wide patient base. All procedures were executed by one oral and maxillofacial surgeon.

Participants: All patients $(\mathrm{N}=50)$ who presented for primary repair of the soft palate cleft were included in the study. Inclusion criteria: written consent from parent(s), and patient cleared as systemically healthy by a pediatric physician. Exclusion criteria: patient(s) with systemic infections (eg, flu) and/or any local infections (eg, tonsillitis). There were 25 males and 25 females with an average age of 7 months and 16 days included in the study.

Methods: Swabs were taken from the surgical site of all 50 patients with cleft soft palate and were sent for culture, identification and antimicrobial sensitivity. The swabs were taken before disinfecting the site as well as after 2 minutes of disinfecting the surgical site with chlorhexidine. Results were compared against each other.

Results: Positive cultures with 28 different pathogenic microorganisms that were identified in 47 patients before cleaning the surgical site with the chlorhexidine. The most dominant pathogens were $K$. pneumonia $(n=22), H$. influenza $(n=18)$ and $S$. aureus $(n=10)$. Of the pathogens found, $13(46 \%)$ were still present on the swabs taken after disinfecting with chlorhexidine. K. pneumonia $(n=13), H$. influenza $(n=\mid I)$ and $S$. aureus $(n=9)$ were still the most prevalent pathogens.

Conclusions: This study demonstrated that $6 \mathrm{I}$ of the total of II 3 pathogens isolated (54\%), survived after 2 minutes of disinfecting the surgical and surrounding area with chlorhexidine, thus intensifying the chances of post-operative infection.

Keywords: Chlorhexidine; Resistance; Pathogens; Cleft soft palate

Corresponding Author: Gieljam Johannes Roode, BChD, MSc(Odont-Oral Surg); ,P/Bag x 323,Arcadia, 0007, South Africa; ,Tel: +27 12319 2234;, Fax: +27 86693 8067; Email: giel.roode@up.ac.za
Received: September 7, 2017

2nd Revision: February 20, 2018

2nd Revision: February 20, 2018

Accepted: March 23, 2018

doi: $10.3121 / \mathrm{cmr} .2018 .1385$

Clinical Trial Registration: Faculty of Health Sciences Research Ethics Committee of the University of Pretoria approval: 467/2015. 
$\mathrm{P}$ athogenic microorganisms with resistance to antimicrobial drugs are a major concern in surgical treatment of facial clefts. ${ }^{1}$ This is especially a factor in the treatment of soft and hard palate clefts where postoperative infection can lead to the formation of oro-nasal fistulas or even breakdown of the whole surgical site. A complication like this will have a detrimental effect on future feeding and speech of the patient creating the need for additional surgical interventions. As more evidence of resistance of pathogenic microorganisms against antimicrobial drugs is published, the question comes to mind: How much resistance has developed against chlorhexidine?

Microorganisms like Klebsiella pneumonia, Haemophilus influenza and Staphylococcus aureus are opportunistic pathogens that are often detected preoperatively in infants that present for the first stage of repair of the soft palate, and these are of increasing importance. ${ }^{1,2}$ The recent outbreaks of carbapenemase-producing $K$. Pneumonia are of great importance..$^{3-5}$

Chlorhexidine was first introduced commercially in the United Kingdom as a disinfectant and topical antiseptic in 1954. ${ }^{6,7}$ It is effective against Gram-negative, Gram-positive bacteria and fungi and kills by disruption of the cell membrane. Thus, it was set as the gold standard for surface and surgical site disinfectant..$^{8-10}$ One study ${ }^{11}$ demonstrated the effectiveness of antimicrobial surgical gloves of which the inner surface is coated with chlorhexidine digluconate (CHG), against $K$. pneumonia after a 2-hour wear time. The authors found that a mean reduction factor of $6 . .^{22} \log 10$ was achieved after 5 minutes' contact. A study done in a "long-term acute care hospital" had success in controlling an outbreak of $K$. pneumonia carbapenemase (KPC)-producing $K$. pneumonia by combining daily $2 \% \mathrm{CHG}$ baths for patients with enhanced environmental cleaning, surveillance cultures at admission, serial point prevalence surveillance (PPS), isolation precautions, and training of personnel. ${ }^{12}$ Numerous additional studies have also confirmed the effectiveness of chlorhexidine $\mathrm{e}^{13-15}$ and, its effectivity against biofilm formation was also proven. ${ }^{16}$ However, other research projects have found that the effectiveness of chlorhexidine against $K$. pneumonia is greatly reduced. ${ }^{17-20}$

A study in a hospital environment in China observed that isolates of $S$. aureus showed reduced susceptibility to chlorhexidine ${ }^{21}$ and was confirmed in Taiwan. ${ }^{22}$ It was also stated that the "reduced microbial susceptibility to biocides represents a serious cause for concern in the clinical environment". ${ }^{23}$ In a study done on soft palate cleft patients, ${ }^{1}$ results indicated that 35 patients out of the total of 200 were infected preoperatively with $K$. pneumonia. This pathogen also showed the highest resistance to antimicrobials. $H$. influenza, S. aureus and 20 other microorganisms were also isolated preoperatively.
The protocol for the first stage of soft palate cleft repair at the Wilgers Surgical Center Pretoria, uses CHG as disinfectant on the area to be operated to remove all pathogenic microorganisms in an effort to minimize postoperative infections as much as possible. In light of above mentioned literature the objective is to determine (1) if chlorhexidine application is effective in removing pathogens from the surgical site in these patients and, if any pathogens were isolated, (2) are they resistant to any other antimicrobials. Answering this objective can guide all surgical disciplines that make use of $\mathrm{CHG}$ as disinfectant of the surgical site.

\section{Methods}

A descriptive observational study was designed and approved by the Faculty of Health Science Research Ethics Committee (467/2015) of the University of Pretoria. All patients $(\mathrm{N}=50)$ that presented for primary repair of the soft palate cleft were included in the study. Only patients where written consent from the parents was received and that were cleared as systemic healthy by a pediatric physician were included in

Table 1: Pathogens identified before disinfecting with chlorhexidine.

\begin{tabular}{lc}
\hline Microorganism & N \\
Acinetobacter baumannii & 2 \\
Aeromonas hydrophila/caviae & 1 \\
Candida albicans & 3 \\
Candida famata & 1 \\
Candida kefyr & 1 \\
Candida krusei & 1 \\
Candida lusitaniae & 1 \\
Candida parapsilosis & 2 \\
Candida tropicalis & 2 \\
Chryseobacterium gleum & 1 \\
Citrobacter freundii & 1 \\
Edwardsiella tarda & 1 \\
Enterobacter cloacae & 9 \\
Escherichia coli & 9 \\
Geobacillus thermoglucosidasium & 1 \\
Haemophilus influenza & 18 \\
Klebsiella oxytoca & 4 \\
Klebsiella pneumonia & 22 \\
Neisseria subflava & 1 \\
Proteus mirabilis & 1 \\
Pseudomonas aeruginosa & 2 \\
Pseudomonas putida & 1 \\
Saccharomyces cerevisiae & 1 \\
Serratia marcescens & 2 \\
Staphylococcus aureus & 10 \\
Streptococcus mitis/oralis & 9 \\
Streptococcus parasanguinis & 2 \\
Streptococcus pneumoniae & 4
\end{tabular}


Table 2: Comparison of the number of pathogens identified before and after cleaning/disinfecting with chlorhexidine.

\begin{tabular}{lcc}
\hline Microorganism & $\begin{array}{c}\text { After } \\
\text { (n) }\end{array}$ & $\begin{array}{c}\text { Before } \\
\text { (N) }\end{array}$ \\
\hline Aeromonas hydrophila/caviae & 1 & 1 \\
Candida albicans & 1 & 3 \\
Candida parapsilosis & 1 & 2 \\
Enterobacter cloacae & 3 & 9 \\
Escherichia coli & 6 & 9 \\
Haemophilus influenza & 11 & 18 \\
Klebsiella oxytoca & 2 & 4 \\
Klebsiella pneumonia & 13 & 22 \\
Pseudomonas aeruginosa & 2 & 2 \\
Staphylococcus aureus & 9 & 10 \\
Streptococcus mitis/oralis & 7 & 9 \\
Streptococcus parasanguinis & 2 & 2 \\
Streptococcus pneumoniae & 3 & 4 \\
\hline
\end{tabular}

the study. Patients with systemic infections (eg, flu) and/or any local infections (eg, tonsillitis) were excluded from the study. History of previous medications prescribed to the patients was not recorded. All procedures were executed by one Oral and Maxillofacial surgeon.

The Copan Transystem Bacteriology Swab Collection system with Amies Agar Gel for aerobic and anaerobic culture was used to collect and transport specimens. The first swab was taken pre-operatively from the cleft soft palate and adjacent nasopharynx of all patients immediately after they were anaesthetized (general anesthesia) by removing the swab from the sterile packing, rubbing it gently against the mucosa of the indicated area, inserting the swab in the transport tube to seal it and marked as "pre-cleaning". Next, the mouth and oropharyngeal area were cleansed (disinfected) with a chlorhexidine solution (Andolex-C Oral Rinse) for 2 minutes. The cleaning was done by using three sterile sponges $(40 \mathrm{~mm}$ x $70 \mathrm{~mm} \times 20 \mathrm{~mm}$ attached to a plastic spatula of $150 \mathrm{~mm}$ ) that were soaked in the chlorhexidine solution. The sponges were applied by rubbing the whole mouth and oro-pharyngeal area consecutively to make up the 2 minutes. A second swab was then taken from the cleft soft palate and nasopharynx and marked as "post-cleaning". All swabs were transported in this format within 1 hour to a laboratory for culturing in order to determine the type, colony size and sensitivity of any possible microorganisms.

The organisms were isolated using standard microbiological methods: all samples were inoculated onto a non-selective blood agar plate as well as a selective and differential MacConkey agar plate. Plates were incubated overnight at 35 degrees Celsius. Next morning, incubated colonies are transferred to a target slide that is introduced into VITEK MS, an automated mass spectrometry microbial identification system for identification of pathogens. Kirby-Bauer antibiotic testing was utilized to determine antimicrobial sensitivity or resistance to indicate which antimicrobial agents will be effective in treating the patient if any infections develop.

Pre-cleaning and post-cleaning data from the laboratory results were recorded per patient and used for analysis. Frequencies and proportions, with $95 \%$ confidence intervals, are used to describe the presence of bacteria in patients, before and after cleaning, as well as the proportion of the bacteria that was eliminated.

\section{Results}

From the swabs taken prior to disinfecting with chlorhexidine, pathogenic microorganisms could be cultured in all but 3 patients $(n=47)$.

The average age of the 50 patients is calculated at 7 months and 16 days (Standard deviation: 3 months and 18 days). There is an equal sex distribution with 25 patients male and 25 female. Race distribution is as follows: Indian (3), Black (10) and White (37).

Of the 47 patients that showed positive cultures, twenty-eight different pathogenic microorganisms were identified (Table 1). K. pneumonia was present in 22 of these patients, $H$. influenza in 18 patients and $S$. aureus in 10 patients. The following microorganisms were isolated in 9 patients each: Enterobacter cloacae, Escherichia coli and Streptococcus mitis/oralis. The rest of the organisms numbered between 1 and 4 patients with 13 of them in only one patient each. A total of 113 pathogens were cultured from the 47 patients (Table 1).

Post-cleaning (disinfecting) cultures isolated 13 different microorganisms that had various levels of resistance to chlorhexidine (Table 2), including 13 of $22(59.1 \%) \mathrm{K}$. pneumomia cases, 11 of $18(61.1 \%) H$. influenza cases, and 9 of $10(90 \%) S$. aureus cases were not eradicated. Also, three organisms, E. cloacae, E. coli and S. mitis/oralis that were present in 9 cases each, had $3(33.3 \%), 6(66.6 \%)$ and 7 $(77.8 \%)$ cases surviving the chlorhexidine treatment, respectively.

This result showed that 61 of the 113 pathogens (54\%) survived after 2 minutes of disinfecting the surgical and surrounding area with CHG (Table 2).

Antimicrobial resistance of the pathogens cultured from the pre-cleaning swabs was determined. 76 of the $113(67.3 \%)$ pathogens showed resistance to different anti-microbial agents that they were tested against. Table 3 is a summary of the resistance of the 6 most prevalent micro-organisms.

\section{Discussion}

Drug resistance is a growing concern in the medical field. It is of utmost importance to ensure that surgical areas be pathogen- 
Table 3. Antibiotic resistance of the 6 most predominant pathogens.

\begin{tabular}{|c|c|c|}
\hline Pathogen (N) & Antibiotic & Resistant cases (n) \\
\hline \multirow[t]{9}{*}{ Klebsiella pneumoniae (22) } & Ampicillin & 21 \\
\hline & Amoxicillin-Clavulanic Acid (I) & 3 \\
\hline & Cefuroxime & 4 \\
\hline & Cefotaxime & 3 \\
\hline & Ceftazidime & 2 \\
\hline & Cefepime & 1 \\
\hline & Amikacin (I) & 1 \\
\hline & Tobramycin (I) & 2 \\
\hline & Cotrimoxazole & 4 \\
\hline \multirow[t]{2}{*}{ Haemophilus influenza (18) } & Cotrimoxazole & 9 \\
\hline & Moxifloxacin & 1 \\
\hline \multirow[t]{3}{*}{ Staphylococcus aureus (10) } & Penicillin-G & 10 \\
\hline & B-lactamase + & 2 \\
\hline & Cotrimoxazole & 1 \\
\hline \multirow[t]{3}{*}{ Enterobacter cloacae (9) } & Ampicillin & 9 \\
\hline & Amoxicillin-Clavulanic Acid & 9 \\
\hline & Cefuroxime & 8 \\
\hline \multirow[t]{7}{*}{ Escherichia coli (9) } & Ampicillin & 6 \\
\hline & Amoxicillin-Clavulanic Acid & 1 \\
\hline & Cefuroxime & 2 \\
\hline & Cefutaxime & 2 \\
\hline & Ciprofloxacin & 1 \\
\hline & Cotrimoxazole & 5 \\
\hline & Tobramycin & 1 \\
\hline \multirow[t]{5}{*}{ Streptococcus mitis/oralis (9) } & Ampicillin & 3 \\
\hline & Penicillin-G & 5 \\
\hline & Amoxicillin-Clavulanic Acid & 4 \\
\hline & Erythromycin & 6 \\
\hline & Clindamycin & 3 \\
\hline
\end{tabular}

free pre-operatively to prevent infection; thus, the use of disinfectants has increased dramatically. Chlorhexidine seems to be the most widely used oral disinfectant ${ }^{8}$ and, as a result, more and more evidence of resistance to chlorhexidine is emerging. ${ }^{17-23}$

In 2002, one research study indicated that strains of microorganisms resistant to antibiotics were also less susceptible to chlorhexidine. ${ }^{24}$ The number of antimicrobial resistant organisms indicated in soft palate cleft patients in the literature ${ }^{1}$ prompted the current study investigating the effectiveness of disinfecting the surgical site with chlorhexidine in these specific cleft patients. Post-cleaning cultures indicated that 61 of the 113 pathogens $(54 \%)$ isolated pre-cleaning survived after 2 minutes of disinfecting the surgical and surrounding area with chlorhexidine demonstrating that it is not as effective as required. More articles were published in current years where lower susceptibility of pathogens against 


\section{Resistant micro-organisms}

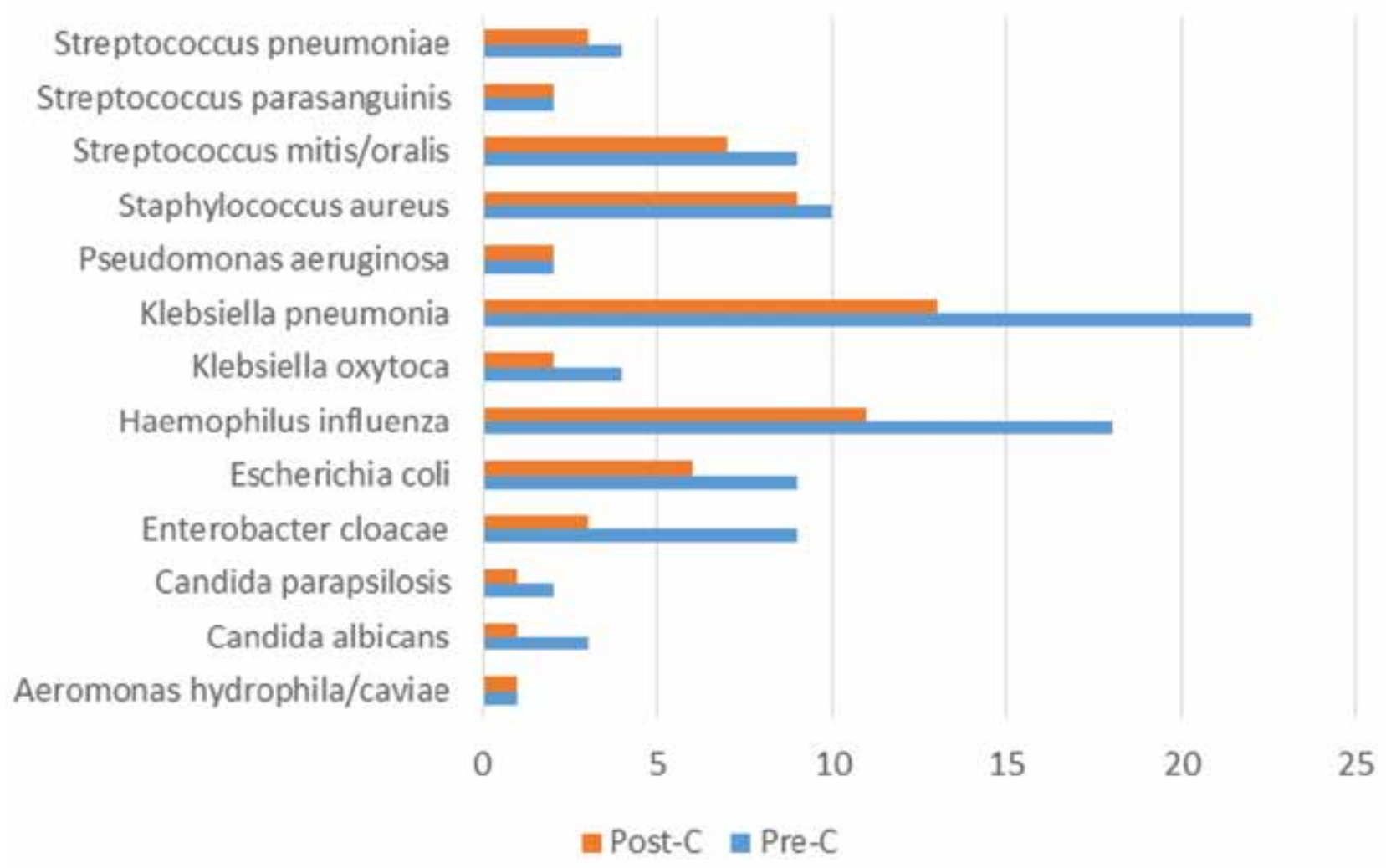

Figure 2. Pathogenic micro-organisms (Post- $\mathrm{C}=$ Post cleaning, Pre- $\mathrm{C}=$ Pre-cleaning)

chlorhexidine was indicated. ${ }^{21}$ One study found that the efficacy of chlorhexidine was weak in comparison to other disinfectants against five pathogens. ${ }^{18}$ This is in line with our study that compared similarly to two of the same pathogens. In general, Gram-positive bacteria are considered more sensitive to disinfectants than Gram-negative bacteria due to the composition of the cell wall. ${ }^{8}$ Of the 13 pathogens surviving chlorhexidine treatment in this study, 7 were Gramnegative, 4 were Gram-positive and 2 were yeasts.

In this descriptive observational study, the authors found that for the pathogen S. aureus, $90 \%$ of cases identified were resistant to chlorhexidine, and this was comparable with other studies that indicated lesser susceptibility to chlorhexidine. ${ }^{21-23}$ For patients where Pseudomonas aeruginosa (2 patients), Streptococcus parasanguinis (2 patients) and Aeromonas hydrophila/caviae (1 patient), 100\% resistance to chlorhexidine was oberved (Figure 1) and is in line with other studies. ${ }^{18,24}$ This is also supported by a study that proved the low susceptibility of Pseudomonas stutzeri. ${ }^{25}$

As far back as 1991, research has indicated the resistance of $K$. pneumonia against chlorhexidine. ${ }^{26}$ One study found that chlorhexidine-resistant subpopulations of $K$. pneumonia were independent of the bacterial sequence type, ${ }^{27}$ while another study proved that Carbapenem-resistant $K$. pneumoniae (CRKP) has pan-resistance to disinfectants. ${ }^{17}$ With this in mind, it is of great concern that 11 fatal cases in one clinical center were connected to CRKP28 as well as 5 deaths in France. ${ }^{29}$ In 2004, the intrinsic contamination of a $2 \%$ chlorhexidine hand soap with $K$. pneumonia was reported.$^{30} \mathrm{In}$ the current study, $K$. pneumonia was the most prominent pathogen cultured pre-cleaning ( 22 of the total of 50 cases) and $13(59.1 \%)$ were resistant to chlorhexidine.

Comparing antimicrobial resistance of pathogens isolated in this study parallels to other studies. ${ }^{1,23,24,27,31}$ Resistance to the more commonly used antimicrobials equates to the following with number of pathogens out of the total of 113 indicated in brackets: ampicillin (20), amoxicillin-clavulanic acid (25), cefuroxime (18), cotrimoxazole (29) and erythromycin (14).

A limitation of this study is that the results apply to a very special group of patients and might not be representative of the general population. Of concern is that such a high number of antimicrobial resistant microorganisms were cultured in a patient group where the average age is 7.5 months.

The purpose of disinfecting a surgical site is to remove all pathogens to prevent post-operative infections. The results of 
this descriptive observational study indicates that $\mathrm{CHG}$ is less than $50 \%$ effective as disinfectant in cleft soft palate patients.

\section{Conclusion}

The resistance of pathogens to the gold standard of disinfectants, chlorhexidine, leads to the more intensive use of antimicrobials to reduce the post-operative complications of infection. This practice is leading to the negative effect of a wider usage of antimicrobials that leads to greater resistance of the pathogens to these antimicrobials. This results indicates that surgeons should refrain from using $\mathrm{CHG}$ as a surgical site disinfectant and use a more effective substitute. A natural alternative like honey, that in vitro does not have any antimicrobial resistance to it, should be tested in vivo for its effectiveness, and it might be an ideal solution.

\section{References}

1. Roode GJ, Bütow KW, Naidoo S. Preoperative evaluation of micro-organisms in non-operated cleft in soft palate: impact on use of antibiotics. Br J Oral Maxillofac Surg 2017;55(2):127-131.

2. Wand ME, Baker KS, Benthall G, et al. Characterization of preantibiotic era Klebsiella pneumoniae isolates with respect to antibiotic/disinfectant susceptibility and virulence in Galleria mellonella. Antimicrob Agents Chemother 2015;59(7):39663972.

3. Ducomble T, Faucheux S, Helbig U, et al. Large hospital outbreak of KPC-2-producing Klebsiella pneumoniae: investigating mortality and the impact of screening for KPC-2 with polymerase chain reaction. J Hosp Infect 2015;89(3):179-185.

4. Lippmann N, Lübbert C, Kaiser T, et al. Clinical epidemiology of Klebsiella pneumoniae carbapenemases. Lancet Infect Dis 2014;14(4):271-272.

5. Giuffrè M, Bonura C, Geraci DM, et al. Successful control of an outbreak of colonization by Klebsiella pneumoniae carbapenemase-producing K. pneumoniae sequence type 258 in a neonatal intensive care unit, Italy. J Hosp Infect 2013;85(3):233-236.

6. About Chlorhexidine. 2017. Available from: http:// chlorhexidinefacts.com/.

7. Davies GE, Francis J, Martin AR, et al. 1:6-Di-4'chlorophenyldiguanidohexane (hibitane); laboratory investigation of a new antibacterial agent of high potency. $\mathrm{Br}$ J Pharmacol Chemother 1954;9(2):192-196.

8. McDonnell G, Russell AD. Antiseptics and disinfectants: activity, action, and resistance. Clin Microbiol Rev 1999;12(1):147-179.

9. Larson EL, Laughon BE. Comparison of four antiseptic products containing chlorhexidine gluconate. Antimicrob Agents Chemother 1987;31:1572-1574.

10. Puig Silla M MCJ, Almerich Silla JM. . Use of chlorhexidine varnishes in preventing and treating periodontal disease: a review of the literature. Med Oral Patol Oral Cir Bucal 2008;13:E257-E260.

11. Leitgeb J, Schuster R, Yee BN, et al. Antibacterial activity of a sterile antimicrobial polyisoprene surgical glove against transient flora following a 2-hours simulated use. BMC Surg 2015;15(1):81.

12. Munoz-Price LS, Hayden MK, Lolans K, et al. Successful control of an outbreak of Klebsiella pneumoniae carbapenemase-producing K. pneumoniae at a long-term acute care hospital. Infect Control Hosp Epidemiol 2010;31(04):341-347.
13. Soares AF, Aquino AR, Carvalho $\mathrm{CH}$, et al. Frequency of oral mucositis and microbiological analysis in children with acute lymphoblastic leukemia treated with $0.12 \%$ chlorhexidine gluconate. Braz Dent J 2011;22(4):312-316.

14. Mann-Salinas EA, Joyner DD, Guymon CH, et al. Comparison of Decontamination Methods for Human Skin Grafts. J Burn Care Res 2015;36(6):636-640.

15. Lin MY, Lolans K, Blom DW, et al; Centers for Disease Control and Prevention Epicenter Program. The effectiveness of routine daily chlorhexidine gluconate bathing in reducing Klebsiella pneumoniae carbapenemase-producing Enterobacteriaceae skin burden among long-term acute care hospital patients. Infect Control Hosp Epidemiol 2014;35(04):440-442.

16. Houari A, Di Martino P. Effect of chlorhexidine and benzalkonium chloride on bacterial biofilm formation. Lett Appl Microbiol 2007;45(6):652-656.

17. Guo W, Shan K, Xu B, et al. Determining the resistance of carbapenem-resistant Klebsiella pneumoniae to common disinfectants and elucidating the underlying resistance mechanisms. Pathogens and Global Health 2015;109(4):184192.

18. Shimizu M, Okuzumi K, Yoneyama A, et al. In vitro antiseptic susceptibility of clinical isolates from nosocomial infections. Dermatology 2002;204(1):21-27.

19. Brown AT, Shupe JA, Sims RE, et al. In vitro effect of chlorhexidine and amikacin on oral gram-negative bacilli from bone marrow transplant recipients. Oral Surg Oral Med Oral Pathol 1990;70(6):715-719.

20. Gautier G, Noguer M, Costa N, et al. Mouthrinses: a comparative microbiological study. Bull Group Int Rech Sci Stomatol Odontol 2000;42(1):23-29.

21. Lu Z, Chen Y, Chen W, et al. Characteristics of qacA/B-positive Staphylococcus aureus isolated from patients and a hospital environment in China. J Antimicrob Chemother 2015;70(3):653-657.

22. Wang JT, Sheng WH, Wang JL, et al. Longitudinal analysis of chlorhexidine susceptibilities of nosocomial methicillinresistant Staphylococcus aureus isolates at a teaching hospital in Taiwan. J Antimicrob Chemother 2008;62(3):514-517.

23. Vali L, Davies SE, Lai LLG, et al. Frequency of biocide resistance genes, antibiotic resistance and the effect of chlorhexidine exposure on clinical methicillin-resistant Staphylococcus aureus isolates. J Antimicrob Chemother 2008;61(3):524-532.

24. Kõljalg S, Naaber P, Mikelsaar M. Antibiotic resistance as an indicator of bacterial chlorhexidine susceptibility. J Hosp Infect 2002;51(2):106-113.

25. Tattawasart U, Maillard JY, Furr JR, et al. Development of resistance to chlorhexidine diacetate and cetylpyridinium chloride in Pseudomonas stutzeri and changes in antibiotic susceptibility. J Hosp Infect 1999;42(3):219-229.

26. Stickler D, Dolman J, Rolfe S, et al. Activity of some antiseptics against urinary tract pathogens growing as biofilms on silicone surfaces. Eur J Clin Microbiol Infect Dis 1991;10(5):410-415.

27. Naparstek L, Carmeli Y, Chmelnitsky I, et al. Reduced susceptibility to chlorhexidine among extremely-drugresistant strains of Klebsiella pneumoniae. J Hosp Infect 2012;81(1):15-19.

28. Shaw G. Breaking News: Deadly Klebsiella Pneumoniae Strain Resistant to Carbapenems. Emergency Medicine News 2013;35:1,38.

29. Decré D, Verdet C, Emirian A, et al. Emerging severe and fatal infections due to Klebsiella pneumoniae in two university hospitals in France. J Clin Microbiol 2011;49(8):3012-3014. 
30. Brooks SE, Walczak MA, Malcolm S, et al. Intrinsic Klebsiella pneumoniae contamination of liquid germicidal hand soap containing chlorhexidine. Infect Control Hosp Epidemiol 2004;25(10):883-885.

31. Suller MTE, Russell AD. Antibiotic and biocide resistance in methicillin-resistant staphylococcus aureus and vancomycinresistant enterococcus. J Hosp Infect 1999;43(4):281-291.

\section{Author Affiliations}

*Gieljam Johannes Roode, BChD, MSc(Odont-Oral Surg); †Kurt-Wilhelm Bütow, MChD(in MFOSurg), Dr Med Dent, DSc(Odont)

*Senior lecturer, Department of Anatomy, University of Pretoria, P/Bag x 323, Arcadia, 0007, South Africa, Email: giel.roode@up.ac.za

†Consultant Professor, Department of Maxillo-Facial and Oral Surgery, University of Pretoria, PO Box 1266,

Pretoria,0001, South Africa; Email:kurt@butow.co.za 